\title{
BACTÉRIAS ENVOLVIDAS NAS MASTITES SUBCLÍNICAS DE CABRA DA REGIÃO DE SALVADOR, BAHIA
}

\section{M.P. Cavalcante ${ }^{1}$, F. Alzamora Filho ${ }^{2}$, M.G.Á.R. Almeida ${ }^{1}$, N.S. Silva ${ }^{1}$, C.G.G. Barros ${ }^{1}$, M.C.A. Silva ${ }^{1}$}

${ }^{1}$ Universidade Federal da Bahia, Escola de Medicina Veterinária, Departamento de Medicina Veterinária Preventiva, Av. Ademar de Barros, 500, CEP 40170-110, Salvador, BA, Brasil. E-mail: mpcavalcante@yahoo. com.br

\section{RESUMO}

A mastite é uma infecção frequente da glândula mamária, sendo a principal doença que afeta o úbere das fêmeas e responsável pelos maiores prejuízos à produção leiteira em caprinos, reduzindo em quantidade e depreciando a qualidade do leite e seus derivados. Nesse estudo foram colhidas amostras de leite de cabras com reação positiva ao CMT, em propriedades localizadas em Bonfim de Feira, Barra do Pojuca, Feira de Santana, Camaçari, Anguera e Antônio Cardoso, todas próximas à Cidade de Salvador, Bahia. Do material coletado foi realizado cultivo bacteriológico em ágar sangue de ovino a 10\%, ágar McConkey e também enriquecido em caldo BHI. O Staphylococcus spp. foi a bactéria de maior prevalência $(90,3 \%)$, seguida de Streptococcus (4,8\%), Micrococcus $(1,6 \%)$ e Enterobacter (1,6\%). Todas as bactérias foram submetidas ao teste de sensibilidade aos antimicrobianos pelo método de difusão em disco, sendo que $54,1 \%$ das estirpes estudadas apresentaram sensibilidade a todas as drogas testadas, e $45,9 \%$ das estirpes identificadas apresentaram resistência a pelo menos um dos antimicrobianos. O presente estudo confirmou o Staphylococcus spp. como a principal bactéria envolvida na etiologia das mastites subclínicas caprinas.

PALAVRAS-CHAVE: Antibióticos, glândula mamária, Staphylococcus spp., caprino.

\section{ABSTRACT}

BACTERIA INVOLVED IN SUBCLINICAL MASTITIS IN GOATS IN THE REGION OF SALVADOR, BAHIA, BRAZIL. Mastitis is a common infection of the mammary gland, the main disease affecting the udder of females, and responsible for major losses in milk production in goats, decreasing the quantity and quality of the milk and its derivatives. In this study milk samples were collected from goats with positive reaction to CMT in properties located in Bonfim de Feira, Barra do Pojuca, Feira deSantana, Camaçari, Anguera and Antônio Cardoso, all of which are places surrounding the city of Salvador, Bahia, Brazil. The samples were submitted to bacteriological culture carried out in agar with $10 \%$ sheep blood, McConkey agar, and agar enriched with BHI broth. Staphylococcus spp. bacteria was the most prevalent (90.3\%), followed by Streptococcus (4.8\%), Micrococcus $(1.6 \%)$ and Enterobacter (1.6\%). All bacteria were subjected to antimicrobial susceptibility testing by the disc diffusion method, revealing that $54.1 \%$ of the strains studied were sensitive to all drugs tested, while $45.9 \%$ of identified strains showed resistance to at least one of antimicrobials. The present study confirmed Staphylococcus spp. as the main bacteria involved in the etiology of subclinical goat mastitis.

KEY WORDS: Antibacterial, mammary gland, Staphylococcus spp., caprine.

\section{INTRODUÇÃO}

Uma grande variedade de micro-organismos pode estar associada à mastite em caprinos, porém as bactérias do gênero Staphylococcus são consideradas os principais agentes etiológicos da infecção intramamária desses animais, predominando as espécies caracterizadas como coagulase positivas (RADOSTITS et al., 2002; CONTRERAs et al., 2007). Dentre estas espé- cies, o $S$. aureus apresenta-se como o patógeno de maior prevalência e patogenicidade, principalmente por produzir uma grande variedade de fatores de virulência, inclusive toxinas termoestáveis capazes de causarem quadros de gastrenterite em humanos (FAGUndes; OliveIra, 2004; Silva et al., 2005; Morandi et al., 2007).

O diagnóstico da mastite é importante, pois auxilia no tratamento e no controle do quadro infec-

${ }^{2}$ Universidade Estadual de Santa Cruz, Departamento de Ciências Agrárias e Ambientais, Ilhéus, BA, Brasil. 
cioso, podendo ser realizado por diversos métodos, como a inspeção e palpação da glândula mamária, avaliação macroscópica do leite através da caneca de fundo escuro e análise microbiológica seguida de antibiograma (DirKSEn et al., 1993; ANDERSON et al., 2005). A contagem de células somáticas (CCS) como método de diagnóstico direto da infecção e o uso do California mastitis test (CMT) como método indireto de diagnóstico são técnicas que têm sido amplamente utilizadas (BRITO et al., 1997; PAAPE et al., 2007). No entanto, considerando que em cabras a CCS reflete de forma menos precisa a ocorrência de infecção intramamária subclínica do que em vacas leiteiras (Boscos et al., 1996; ConTrERAs et al., 2007), alguns autores têm recomendado o CMT como um método indireto mais seguro e específico para avaliação das mastites subclínicas em cabras (CONTRERAS et al., 1996; LANGONI et al., 2006).

Uma vez apresentado resultado positivo ao CMT, o exame confirmatório para o diagnóstico é a análise microbiológica do leite. Após a identificação do micro-organisno deve-se realizar o teste de sensibilidade aos antimicrobianos com o objetivo de avaliar qual a melhor droga a ser utilizada no caso específico da mastite. (BRITO et al., 1999; MATEU; Martin, 2001; Contreras et al., 2007). A antibioticoterapia visa à eficiência terapêutica e os benefícios econômicos, como o aumento da produção de leite e a redução das fontes de infecção. Por isso, sempre que possível, o tratamento clínico das mastites com antimicrobianos deve ser baseado em testes de sensibilidade in vitro (CostA, 2002).

A mastite gera graves prejuízos econômicos, como descarte de leite, custo com medicamentos, redução da qualidade e quantidade do leite (МотА, 2008) e, sob o ponto de vista da saúde pública, são frequentes os casos de doenças associadas ao consumo de leite ou derivados lácteos contaminados por microorganismos patogênicos (FAGUNDES; OliveIrA, 2004). Desta forma, o objetivo desse estudo foi investigar os agentes etiológicos bacterianos mais comuns da mastite e a sensibilidade in vitro aos antimicrobianos das estirpes bacterianas isoladas de amostra de leite de cabras com infecção clínica e subclínica.

\section{MATERIAL E MÉTODOS}

As amostras de leite foram obtidas de 218 fêmeas caprinas em lactação, de raças e idades diversas, destinadas ao corte ou a produção de leite, em nove propriedades localizadas em Bonfim de Feira, Barra do Pojuca, Feira de Santana, Camaçari, Angüera e Antônio Cardoso, todas próximas à Cidade de Salvador, Bahia. As coletas foram realizadas no período de agosto a dezembro de 2007 e encaminhadas em recipientes isotérmicos com gelo reciclável ao
Laboratório de Bacterioses (LABAC) do Hospital de Medicina Veterinária da Universidade Federal da Bahia(UFBA), ondeforam devidamente processadas.

Asfêmeas foram avaliadas quanto aos parâmetros fisiológicos e presença de sinais clínicos de mastite através de inspeção do úbere (DIRKSEN et al., 1993). Posteriormente, avaliou-se o leite desses animais através do teste de tamis, onde foram observadas cor, consistência da secreção e presença de massas ou grumos com o objetivo de identificar casos suspeitos de mastite clínica. Em seguida, as fêmeas foram submetidas ao California mastitis test (CMT), onde se coletava cerca de $2 \mathrm{~mL}$ de leite e se adicionava igual volume de detergente aniônico (CONTRERAS et al.,1996), considerando-se positivas as amostras quando havia a formação de um gel firme, correspondente a formação de duas a três cruzes para leite bovino. Somente as amostras de leite consideradas positivas foram coletadas e enviadas ao laboratório para análises microbiológicas.

Para analisar as amostras de leite, semearam-se $30 \mu \mathrm{L}$ de cada amostra positiva em ágar sangue de ovino a 10\% e em ágar McConkey (Himedia Laboratoties Put. Ltd. - India) que foram incubados em aerobiose $\mathrm{a} 36^{\circ} \mathrm{C}$, com leituras em 24 e 48 horas. Uma alíquota de $30 \mu \mathrm{L}$ de cada amostra positiva de leite também foi semeada em caldo de enriquecimento BHI (Himedia Laboratoties Put. Ltd.-India), incubados em aerobiose a $36^{\circ} \mathrm{C}$, com leituras em 24 e 48 horas. Após o período de incubação, uma alíquota dos tubos de caldo BHI com crescimento bacteriano foi semeada em Ágar sangue de carneiro a 10\%. A partir das colônias isoladas foram feitos esfregaços bacteriológicos, os quais foram corados pelo método deGram, observados ao microscópioóptico quantoà sua morfologia e arranjo bacteriano, sendo os microorganismos posteriormente identificados através de provas bioquímicas de rotina (KonEmAn et al., 2001).

Após o isolamento e a identificação realizouse a análise da sensibilidade in vitro dos microorganismos isolados frente aos antimicrobianos pelo método de difusão em disco, conforme técnica descrita por BAUER et al. (1966). Todas as bactérias isoladas a partir das amostras de leite estudadas foram submetidas ao teste de sensibilidade aos seguintes antimicrobianos: amoxacilina $(10 \mu \mathrm{g})$, amoxacilina com ácido clavulônico $(30 \mu \mathrm{g})$, ampicilina $(10 \mu \mathrm{g})$, cefalônio anidro $(30 \mu \mathrm{g})$, cefalotina $(30 \mu \mathrm{g})$, gentamicina $(10 \mu \mathrm{g})$, norfloxacina $(10 \mu \mathrm{g})$, novobiocina $(30 \mu \mathrm{g})$, sulfazotrim $(25 \mu \mathrm{g})$ e tetraciclina $(30 \mu \mathrm{g})$. As bactérias Gram positivas foram ainda testadas quanto à sensibilidade à estreptomicina $(10 \mu \mathrm{g})$, oxacilina $(1 \mu \mathrm{g})$ e penicilina (10 UI), enquanto para as bactérias Gram negativas testou-se, ainda, a polimixina B (300 UI). A interpretação dos resultados seguiu as recomendações do National Comitte for Clinical Laboratory Standards (NCCLS, 2000). 


\section{RESULTADOS}

Do total de 218 fêmeas avaliadas, 58 (26,6\%) delas apresentaram resultado positivo ao CMT, das quais foram coletadas para exame bacteriológico as 107 amostras de leite que foram positivas ao teste. Desse total de amostras, 61 (57\%) revelaram crescimento bacteriano e, após correlacionar os resultados bacteriológicos encontrados com o total de fêmeas positivas para CMT (58 animais), verificou-se que $82,7 \%$ (48 animais) das fêmeas com reação positiva ao CMT apresentavam mastite subclínica. Durante a coleta das amostras, apenas dois casos de mastite clínica $(3,4 \%)$ foram observados, uma causada por Staphylococcus coagulase negativa e outra causada por uma infecção mista de Streptococcus spp. e Micrococcus spp.

Observou-se também que tetos considerados desbalanceados, ou seja, tetos grandes e disformes, corresponderam a $46,4 \%$ das fêmeas portadoras de mastite subclínica, contra 26,8\% de fêmeas com tetos pequenos, e igual percentual de fêmeas com tetos considerados firmes e balanceados. A prevalência de amostras positivas com crescimento bacteriano na glândula esquerda foi maior $(46,4 \%)$ do que na glândula direita $(26,8 \%)$ e do que em fêmeas que tinham as duas glândulas comprometidas $(26,8 \%)$. Não houve relação entre o tipo de teto e o lado da glândula comprometida.

Do total de micro-organismos isolados das mastites subclínicas estudadas, 98,4\% eram bactérias, e em apenas uma amostra (1,6\%) foi possível isolar leveduras. Quase todas as mastites foram causadas por um único agente $(93,8 \%)$, com exceção de três casos $(6,2 \%)$ onde havia infecção mista, sendo que uma fêmea apresentava infecção por Streptococcus spp. e Staphylococcus epidermidis na mesma glândula e as outras duas apresentavam infecção por Streptococcus spp., Micrococcus spp., S. epidermidis e leveduras, porém um único tipo de patógeno em cada glândula. Nos três casos, os isolados bacterianos apresentavam resistência à maioria dos antimicrobianos testados e todas as fêmeas faziam parte do mesmo rebanho.

Das bactérias isoladas, a maior prevalência foi de Staphylococcus spp. (90,3\%), sendo o S. aureus $(29,5 \%)$ o agente mais isolado, seguido do $S$. intermedius $(26,2 \%)$, S. epidermidis $(21,3 \%)$ e outros Staphylococcus coagulase negativa $(14,7 \%)$. Também foram isolados Streptococcus spp. (4,9\%), Micrococcus spp. $(1,7 \%)$ e Enterobacter spp. (1,7\%). Todas as bactérias isoladas foram submetidas ao teste de sensibilidade aos antimicrobianos, onde 54,1\% apresentaram sensibilidade a todos os agentes e $45,9 \%$ apresentaram resistência a um ou mais antimicrobianos testados (Tabela 1).

As espécies bacterianas pertencentes ao gênero Staphylococcus spp. apresentaram maior sensibilidade aos antimicrobianos testados, enquanto as espécies pertencentes aos demais gêneros bacterianos encontrados apresentaram resistência a pelo menos um dos antimicrobianos testados, porém o número de estirpes isoladas foi pequeno para que se pudesse fazer uma melhor avaliação desse resultado.

Tabela 1 - Bactérias isoladas de mastites subclínicas em cabras e perfil de sensibilidade aos antimicrobianos.

\begin{tabular}{lccc}
\hline Bactérias isoladas & Total de isolados & Isolados sensíveis & Isolados resistentes \\
\hline S. aureus & 18 & 11 & 7 \\
& $(29,5 \%)$ & $(61,1 \%)$ & $(38,9 \%)$ \\
S. intermedius & 16 & 10 & $(37,5 \%)$ \\
& $(26,2 \%)$ & $(62,5 \%)$ & 6 \\
S. epidermidis & 13 & 7 & $(46,2 \%)$ \\
Staphylococcus coagulase negativa & $(21,3 \%)$ & $(53,8 \%)$ & 4 \\
& $(14,7 \%)$ & 5 & $(44,5 \%)$ \\
Streptococcus spp. & 3 & $(55,5 \%)$ & 3 \\
Micrococcus spp. & $(4,9 \%)$ & 0 & $(100 \%)$ \\
& 1 & $(0 \%)$ & 1 \\
Enterobacter spp. & $(1,7 \%)$ & 0 & $(100 \%)$ \\
\hline Total de amostras & 1 & $(0 \%)$ & 1 \\
\hline
\end{tabular}


Todos os isolados bacterianos apresentaram-se sensíveis à polimixina $\mathrm{B}(\mathrm{PMX})$, amoxacilina (AMX) e à associação de amoxacilina com ácido clavulônico $(\mathrm{AMX}+\mathrm{C})$. Com relação aos demais antimicrobianos, pelo menos uma das amostras apresentou resistência. Todas as espécies de Staphylococcus spp. apresentaram, ainda, sensibilidade à amoxacilina (AMX), cefalônio anidro (CFN), gentamicina (GEN), norfloxacina (NOR) e oxaciclina (OXA). Ainda com relação às espécies bacterianas desse gênero, os antimicrobianos aos quais a maioria das estirpes apresentou resistência foram: ampicilina (AMP) (43,5\%), estreptomicina (EST) $(47,8 \%)$ epenicilina (PEN) $(52,2 \%)$. Os resultados estão descritos nas Tabelas 2 e 3.

Tabela 2 - Estirpes de Staphylococcus spp. isoladas de cabras com mastites subclínicas submetidas ao teste de sensibilidade aos antimicrobianos que apresentaram resistência a um ou mais antimicrobianos

\begin{tabular}{|c|c|c|c|c|c|}
\hline \multicolumn{6}{|c|}{ Isolados de Staphylococcus spp. resistentes aos antimicrobianos } \\
\hline & S. aureus & S .intermedius & S. epidermidis & $\mathrm{SCN}^{+}$ & Total de isolados \\
\hline Total de isolados & 7 & 6 & 6 & 4 & 23 \\
\hline AMX & 0 & 0 & 0 & 0 & 0 \\
\hline $\mathrm{AMX}+\mathrm{C}$ & 0 & 0 & 0 & 0 & 0 \\
\hline AMP & 0 & $\begin{array}{l}34^{*} 38^{*} 49^{*} \\
64^{*} 65^{*} 88^{*}\end{array}$ & $28^{*} 55^{*}$ & $84^{*} 89^{*}$ & 10 \\
\hline CFN & 0 & $\begin{array}{ccc}04 & 03 & 0 \\
0 & 0\end{array}$ & 0 & 0 & 0 \\
\hline CFL & 0 & 0 & 55 & 0 & 1 \\
\hline EST & $\begin{array}{lll}07 * 30 * & 40 * \\
82 * & 83 * & 91 *\end{array}$ & $\begin{array}{l}34^{*} \\
38^{*}\end{array}$ & $100^{*} 101^{*}$ & $20^{*}$ & 11 \\
\hline GEN & $\begin{array}{rrr}02 & 0 \\
0 & 0\end{array}$ & $\begin{array}{r}50 \\
0\end{array}$ & 0 & 0 & 0 \\
\hline NOR & 0 & 0 & 0 & 0 & 0 \\
\hline NOV & $40^{*}$ & 0 & $\begin{array}{l}05^{*} \\
06^{*}\end{array}$ & $20^{*}$ & 4 \\
\hline OXA & 0 & 0 & 0 & 0 & 0 \\
\hline PEN & $40^{*}$ & 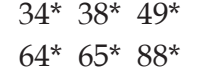 & $05^{*} 06^{*} 55^{*}$ & $66^{*} 89 *$ & 12 \\
\hline SUF & 0 & $64^{*} 65^{*}$ & $05^{*} 06^{*} 55^{*}$ & $66^{*}$ & 6 \\
\hline TET & $91^{*}$ & $64^{*} 65^{*} 88^{*}$ & $55^{*}$ & $66 * 89 *$ & 7 \\
\hline
\end{tabular}

*Staphylococcus coagulase negativa; AMX: amoxaciclina; AMX + C: amoxaciclina + ácido clavulônico; AMP: ampicilina; CFN: cefalônio anidro; CFL: cefalotina; EST: estreptomicina; GEN: gentamicina; NOR: norfloxacina; NOV: novobiocina; OXA: oxaciclina; PEN: penicilina; SUF: sulfazotrim; TET: tetraciclina. *identificação laboratorial do autor de cada uma das estirpes resistentes.

Tabela 3 - Estirpes de Streptococcus spp., Micrococcus spp. e Enterobacter spp. isoladas de cabras com mastites subclínicas submetidas ao teste de sensibilidade aos antimicrobianos que apresentaram resistência a um ou mais antimicrobianos.

\begin{tabular}{lcccc}
\hline \multicolumn{5}{c}{ Estirpes bacterianas resistentes } \\
\hline Total de estirpes & Streptococcus spp. & Micrococcus spp. & Enterobacter spp. & Total de estirpes \\
AMX & 3 & 1 & 1 & 5 \\
AMX+C & 0 & 0 & 0 & 0 \\
AMP & $55^{*} 58^{*}$ & $59^{*}$ & $41^{*}$ & 4 \\
CFN & 0 & 0 & $41^{*}$ & 1 \\
CFL & 0 & 0 & $41^{*}$ & 1 \\
GEN & $55^{*} 58^{*}$ & $59^{*}$ & $41^{*}$ & 4 \\
NOR & $55^{*} 58^{*}$ & $59^{*}$ & 0 & 3 \\
NOV & 0 & $59^{*}$ & 0 & 1 \\
PMX & 0 & $59^{*}$ & 0 & 1 \\
SUF & 0 & 0 & 0 & 0 \\
TET & $39^{*} 55^{*} 58^{*}$ & $59^{*}$ & 0 & 4 \\
*Staphylococus & $59^{*} 58^{*}$ & $41^{*}$ & 4
\end{tabular}

*Staphylococcus coagulase negativa; AMX: amoxaciclina; AMX+C: amoxaciclina + ácido clavulônico; AMP: ampicilina; CFN: cefalônio anidro; CFL: cefalotina; GEN: gentamicina; NOR: norfloxacina; NOV: novobiocina; PMX: polimixina B; SUF: sulfazotrim; TET: tetraciclina. * identificação laboratorial do autor de cada uma das estirpes resistentes. 
O reduzido número de isolados bacterianos pertencentes às espécies Streptococcus spp., Micrococcus spp. e Enterobacter spp. encontrado nesse trabalho não permitiu avaliar com precisão o impacto dessas estirpes quanto ao perfil de sensibilidade aos antimicrobianos, salientando que algumas estirpes desses gêneros apresentaram resistência a mais de três antimicrobianos testados (Tabela 3).

Ainda com relação às Tabelas 2 e 3 , ao analisar o perfil de sensibilidade aos antimicrobianos de cada uma das estirpes isoladas, observa-se que algumas apresentam elevada resistência a quatro ou mais drogas estudadas, indicando a múltipla resistência delas.

\section{DISCUSSÃO}

A mastiteocasiona elevados prejuízos econômicos ao produtor, devido à redução na quantidade e na qualidade do leite, custos com medicamentos e descarte doleite contaminado por micro-organismos ou com resíduos de antimicrobianos (FONSECA; SANTOS, 2000). Pesquisas em rebanhos de caprinos leiteiros indicam a ocorrência de mastite em 13 a 15\% das cabras lactantes (ANDERSON et al., 2005), sendo que até $37 \%$ dos animais do rebanho podem apresentar mastite subclínica (Silva et al., 2005). No presente estudo, observou-se ocorrência de mastite subclínica variando de $12,9 \%$ a $41,7 \%$ nas propriedades pesquisadas, índices muito próximos daqueles encontrados por estudos similares. Segundo um estudo realizado por White; HincKLey (1999), a prevalência de mastite em caprinos, totalizando 1.061 casos clínicos e subclínicos, foi de $36,4 \%$. Das cabras avaliadas com resultado positivo ao CMT, apenas $22 \%$ comprovaram ter mastite subclínica através de exames microbiológicos do leite. Esses resultados são menores do que outros encontrados na literatura. White; Hinckley (1999) verificaram contagem de células elevada em 43,9\% das amostras de leite com cultura negativa e MuRIcy et al. (2002) verificaram um número maior de amostras positivas no CMT comparadas às amostras positivas para cultura microbiológica. Também SchMIDT et al. (2009) identificaram 54 (22,7\%) metades mamárias reagentes ao $\mathrm{CMT}$, das quais oito amostras apresentaram isolamento bacteriano, revelando uma fraca associação entre o CMT e o isolamento microbiano. Ao contrário, estudos realizados por NDEGWA et al. (2000) encontraram um maior número de exames bacteriológicos positivos do que de CMT.

ACCS mais elevada na espéciecaprina éatribuída à maneira como o leite é secretado pela glândula mamária, classificada como apócrina, ondeo produto da secreção é eliminado juntamente com pequena parte da célula, o que determina um elevado número de células epiteliais e partículas citoplasmáticas no leite, constituintes do processo fisiológico normal dos animais (Boscos et al., 1996; CONTRERAs et al., 1996; Perrin et al., 1997; Contreras et al., 2007;). Alguns autores relatam que o aumento dos valores na CCS de caprinos pode estar relacionado, além de uma infecção intramamária, com estágio e número de lactação, idade, raça, alimentação, quantidade de leite produzida, estresse e o estro (Boscos et al., 1996; GoMes et al., 2006; PAAPE et al., 2007). Através dessa pesquisa, pode-se observar que as amostras que apresentaram CMT de duas $(++)$ e três $(+++)$ cruzes, tiveram crescimento bacteriano laboratorial de $82,75 \%$ em relação ao total de fêmeas positivas ao CMT, concordando com os resultados encontrados por Silva et al. (1996) e PeRRIN et al. (1997).

A proporção de isolados positivos encontrada nesse trabalho foi maior na glândula esquerda (59,8\%) do que na glândula direita $(40,2 \%)$, o que concorda com o que foi encontrado por Boscos et al. (1996) em um trabalho realizado na Grécia. Já a prevalência foi maior em mastite subclínica de apenas uma glândula $(73,2 \%)$ do que em ambas as glândulas $(26,8 \%)$. MoRONI et al. (2005), em um estudo realizado na Itália, de 4.571 fêmeas em lactação avaliadas, observaram que $40,2 \%$ apresentavam algum tipo de crescimento bacteriano. Dessas fêmeas, 52,3\% tinham infecção unilateral e as demais infecção bilateral.

Quanto à prevalência das bactérias encontradas no presente estudo, os dados concordam com diversos trabalhos que apontam o Staphylococcus spp. como o principal agente causador da mastite caprina (Deinhofer; Pernthaner, 1995; Fernandes, 2002; AJuWAPE et al., 2005). O S. aureus é considerado o agente etiológico mais importante envolvido na mastite dos caprinos, tanto por ser o mais isolado quanto pela patogenicidade (Sol et al., 2000). Em trabalho realizado na Noruega, JorGENSEN et al. (2005) detectaram a presença de S. aureus em $96,2 \%$ das amostras de leite caprino.

Em um estudo realizado por MARIANO (2007) no Rio de Janeiro, cerca de $19,6 \%$ das amostras isoladas foram de estirpes de Staphylococcus spp. produtoras de toxinas, sendo $38,8 \%$ delas foram identificadas como S. aureus. Deinhofer; Pernthaner (1995) encontraram $84,4 \%$ de Staphylococcus spp. sendo a maioria coagulase negativa $(82,2 \%)$, como agentes causadores de mastite em caprinos. Segundo FAGUNDES; OlIVEIRA (2004), o S. aureus está amplamente distribuído nos rebanhos leiteiros e deve-se ressaltar a importância do homem como reservatório e principal veiculador desse micro-organismo. WHITE; HiNCKLEY (1999) relataram que o micro-organismo mais isolado em leite de cabras era o Staphylococcus spp. não hemolítico $(38,2 \%)$, provavelmente originário da pele do úbere ou da mão do ordenhador, e que o $S$. aureus $(11 \%)$ foi o segundo mais isolado. Outros cocos Gram positivos, como os Streptococcus 
spp. e o $S$. agalactiae também estavam presentes em 4,1\% das infecções. Em relação aos bastonetes Gram negativos, a Escherichia coli e a Pseudomonas spp. estavam presentes, respectivamente, em 1,6\% e 1,4\% das infecções.

Estudos indicam que das bactérias encontradas como agentes de mastite, a prevalência maior foi Staphylococcus coagulase negativo, seguida do $S$. aureus e do Streptococcus spp. (Boscos et al., 1996, Contreras et al., 1996; Moroni et al., 2005). No Brasil, FERNANDES (2002) observou que, das amostras de leite caprino positivas ao exame microbiológico, cerca de $29,5 \%$ apresentavam estafilococos coagulase negativa (SCN) e 1,3\% S. aureus. Estudos mais recentes confirmam que as mastites subclínicas por SCN são as maiores causas de infecções intramamárias em pequenos ruminantes (AJUWAPE et al., 2005; LETINER et al., 2008, ScHMid et al.; 2009). Os resultados encontrados no presente estudo estão de acordo com outros realizados em mastite caprina, onde os agentes mais isolados foram os Staphylococcus coagulase negativa seguidos de $S$. aureus e Streptococcus spp.

Neste trabalho, cerca de $54,1 \%$ das bactérias isoladas apresentaram sensibilidade a todas as drogas testadas, enquanto aproximadamente 45,9\% mostraram-se resistentes a um ou mais antimicrobianos. Podemos observar que o gênero Staphylococcus foi o que apresentou maior sensibilidade aos antimicrobianos testados. Além disso, as estirpes de microorganismos que apresentaram resistência a pelo menos seis antibacterianos testados foram isoladas de casos de mastite subclínica de animais provenientes do mesmo rebanho, provavelmente devido ao uso indiscriminado da medicação e a falhas nos tratamentos anteriores de mastite.

\section{CONCLUSÕES}

O Staphylococcus spp. é o agente etiológico mais encontrado em mastites nas propriedades de criação de caprinos localizadas próximas a Salvador, Bahia. Observando uma maior frequência de infecção mamária causada por estafilococos coagulase-positiva do que por estafilococos coagulase-negativa.

A maioria dos Staphylococcus spp. isolados mostrou-se sensível a grande parte dos antimicrobianos destinados ao tratamento de mastite encontrados no mercado. Bactérias pertencentes a outros gêneros apresentaram resistência a múltiplos antimicrobianos, sugerindo a seleção de estirpes multirresistentes nos plantéis caprinos da região estudada.

Com relação ao uso do CMT como método de triagem para o diagnóstico presuntivo da mastite caprina, o resultado de duas $(++)$ e três $(+++)$ cru- zes parece ser um bom indicativo da ocorrência de mastite subclínica nessa espécie.

\section{AGRADECIMENTOS}

Ao Fundo de Amparo à Pesquisa do Estado da Bahia (FAPESB) pela bolsa de estudos concedida e à Profa. Dra. Eugênia Márcia de Deus Oliveira (in memoriam) pela ajuda imprescindível na realização do presente estudo.

\section{REFERÊNCIAS}

AJUWAPE, A.T.P.; ROBERTS, A.A.; SOLARIN, O.O.; ADETOSOYE, A.I. Bacteriological and haematological studies of clinical mastitis in goats in Ibadan, Oyo State, Nigeria. Small Ruminant Research, v.60, p.307-310, 2005.

ANDERSON, D.E.; HULL, B.L.; PUGH, D.G. Enfermidades da glândula mamária. In: PUGH, D.G. (Ed.). Clínica de ovinos e caprinos. São Paulo: Roca, 2005. p.379-399.

BAUER, A.W.; KIRBY, W.M.M.; SHERRIS, I.C.; TURCK, M. Antibiotics susceptibility testing by standardized single disk method. American Journal of Clinical Pathology, v.45, p.493-496, 1966.

BOSCOS, S.C.; STEFANAKIS, A.; ALEXOPOULOS, C.; SAMARTZI, F. Prevalence of subclinical mastitis and influence of breed, parity, stage of lactation and mammary bacteriological status on coulter counter counts and California Mastitis Test in the milk of Saanem and autochthonous greek goats. Small Ruminant Research, v.21, p.139-147, 1996.

BRITO, J.R.F.; CALDEIRA, G.A.V.; VERNEQUE, R.S.; BRITO, M.A.V.P. Sensibilidade e especificidade do "California Mastitis Test" como recurso diagnóstico da mastite subclínica em relação à contagem de células somáticas. Pesquisa Veterinária Brasileira, v.17, n.2, p.49-53, 1997.

BRITO, M.A.V.P.; BRITO, J.R.F.; RIBEIRO, M.T.; VEIGA, V.M.O. Padrão de infecção intramamária em rebanhos leiteiros: exame de todos os quartos mamários das vacas em lactação. Arquivo Brasileiro de Medicina Veterinária e Zootecnia, v.51, n.2, p.129135, 1999.

CONTRERAS, A.; SIERRA, D.; CORRALES, J. C.; SÁNCHEZ, A.; MARCO, J. Physiological threshold of somatic cell count and California Mastitis Test for diagnosis of caprine subclinical mastitis. Small Ruminant Research, v.21, p.259-264, 1996.

CONTRERAS, A.; SIERRA, D.; SÁNCHEZ, A.; CORRALES, J.C.; MARCO, J.C.; PAAPE, M.J.; GONZALO, 
C. Mastitis in small ruminants. Small Ruminant Research, v.68, p.145-153, 2007.

COSTA, E.O. Uso de antimicrobianos na mastite. In: SPINOSA, H.S.; GÓRNIAK, S.L.; BERNARDI, M.M. (Ed.). Farmacologia aplicada à medicina veterinária. 3.ed. Rio de Janeiro: Guanabara Koogan, 2002. p.443-455.

DEINHOFER, M.; PERNTHANER, A. Staphylococcus spp. as mastitis-related pathogens in goat milk. Veterinary Microbiology, v.43, p.161-166, 1995.

DIRKSEN, G.; GRÜNDER, H. D.; STÖBER, M. Rosenberger: exame clínico dos bovinos. 3.ed. Rio de Janeiro: Guanabara Koogan, 1993. 419p.

FAGUNDES, H.; OLIVEIRA, C.A.F. Infecções intramamárias causadas por Staphylococcus aureus e suas implicações em saúde pública. Ciência Rural, v.34, n.4, p.1315-1320, 2004.

FERNANDES, M.A. Avaliação das características físicoquímicas, celulares e microbiológicas do leite de cabras, da raça Saanen e Alpina, criadas no Estado de São Paulo. 2002, 152f. Tese (Doutorado) - Faculdade de Medicina Veterinária e ZootecniaUniversidade de São Paulo, São Paulo, 2002.

FONSECA, L.F.L.; SANTOS, M.V. Qualidade do leite e controle de mastite. ão Paulo. Lemos Editorial. 2000. 175p.

GOMES, V.; LIBERA, A.M.M.P.D.; PAIVA, M.; MADUREIRA, K.M.; ARAÚJO, W.P. Effect of the stage of lactation on somatic cell counts in healthy goats (Caprae hircus) Breed in Brazil. Small Ruminant Research, v.64, p.30-34, 2006.

JORGENSEN, H.J.; MORK, T.; RORVIK, L.M. Enterotoxigenic Staphylococcus aureus in bulk milk Norway. Journal of Applied Microbiology, v.99, p.158166, 2005.

KONEMAN, E.W.; ALLEN, S.D.; JANDA, W.M.; SCHRECKENBERGUER, P.C.; WINN JUNIOR, W.C. Diagnóstico microbiológico - texto e atlas colorido. 5.ed. Rio de Janeiro: Guanabara Koogan, 2001.

1465 p.

LANGONI, H.; DOMINGUES, P.F.; BALDINI, S. Mastite caprina: seus agentes e sensibilidade frente a antimicrobianos. Revista Brasileira Ciência Veterinária, v.13, n.1, p.51-54, 2006.

LEITNER, G., SILANIKOVE, N., MERIN, U. Estimate of milk and curd yield loss of sheep and goats with intrammamary infection and its relation to somatic cell count. Small Ruminant Research, v. 74, p.221-225, 2008.

MARIANO, F.A.; FOLLY, M.M.; TEIXEIRA, G.N.; CARMO, L.S.; MOTTA, O.V. Produção de enterotoxinas por Stapphylococcus isolados de leite de cabras do estado do
Rio de Janeiro. Revista Brasileira Ciência Veterinária, v.14, n.2, p.105-110, 2007

MATEU, E.; MARTIN, M. Why is anti-microbial resistance a veterinary problem as well? Journal of Veterinary Medicine Series B-Infectious Diseases and Veterinary Public Health, v.48, p.569-581, 2001.

MORANDI, S.; BRASCA, M.; LODI, R.; CREMONESI, P.; CASTIGLIONI. Detection of classical enterotoxins and identification of enterotoxin genes in Staphylococcus aureus from milk and dairy products. Veterinary Microbiology, v.124, p.66-72, 2007.

MORONI, P.; PISONI, G.; RUFFO, G.; BOETTCHER, P.J. Risk factors for intramamary infections and relationship with somatic-cell counts in italian dairy goats. Preventive Veterinary Medicine, v.69, p.163-173, 2005.

MOTA, R.A. Aspectos epidemiológicos, diagnóstico e controle das mastites em caprinos e ovinos. Tecnologia \& Ciência Agropecuária, v.2, n.3, p.57-61, 2008.

MURICY, R.F.; SELLA, A.; SILVA, L.E.; SCHMIDT, V.; CARDOSO, M.I. Identificação de pontos de contaminação do leite produzido em uma propriedade de caprinos no município de Viamão, Rio Grande do Sul, Brasil. Revista da Faculdade de Zootecnia, Veterinária e Agronomia, v.9, n.1, p.111-117, 2002.

NATIONAL COMMITTEE FOR CLINICAL LABORATORY STANDARDS. Aproved Standards M2-A6. Performance standards for antimicrobial disk susceptibility tests. 4.ed. Villanova: Approved Standards. NCCLS, 2000.

NDEGWA, E.N.; MULEI, C.N.; MUNYUA, S.J. The prevalence of subclinical mastitis in dairy goats in Kenya. Journal of the South African Veterinary Association, v.71, n.1, p.25-27, 2000.

PAAPE, M.J.; WIGGANS, G.R.; BANNERMAN, D.D.; THOMAS, D.L.; SANDERS, A.H. CONTRERAS, A.; MORONI, P.; MILLER, R.H. Monitoring goat and sheep milk somatic cell counts. Small Ruminant Research, v.68, p.114-125, 2007.

PERRIN, G.G.; MALLEREAU, M.P.; LENFANT, D.; BAUDRY, C. Relationship between California Mastitis Test (CMT) and somatic cell counts in dairy goats. Small Ruminant Research, v.26, p.167-170, 1997.

RADOSTITS, O.M.; GAY, C.C.; BLOOD, D.C.; HINCHCLIFF, K.W. Clínica veterinária - um tratado de doenças dos bovinos, ovinos, suínos, caprinos e eqüinos. 9.ed. Rio de Janeiro: Guanabara Koogan, 2002. c. 4, 15-20, p.137-140, 541-870.

SCHMIDT, V.; PINTO, A.T.; SCHNEIDER, R.N.; SILVA, F.F.P.; MELLO, F.A. Caracterização da mastite subclínica em caprinos produzidos em sistema orgânico no 
Rio Grande do Sul. Pesquisa Veterinária Brasileira, v.29, p.774-778, 2009.

SILVA, E.R. da; SAUKAS, T.N.; ALVES, F.S.F.; PINHEIRO, R.R. Contagem de células somáticas e California Mastitis Test no diagnóstico da mastite caprina subclínica. Revista Brasileira de Medicina Veterinária, v.18, p.78-83, 1996.

SILVA, E.R.; CARMO, L.S.; SILVA, N. Detection of the enterotoxins A, B and C genes in Staphylococcus aureus from goat and bovine mastitis in brazilian dairy herds. Veterinary Microbiology, v.106, p.103107, 2005.
SOL, J.; SAMPIMON, O.C.; BARKEMA, H.W.; SCHUKKEN, Y.H. Factors associated, with cure after therapy of clinical mastitis caused by Staphylococcus aureus. Journal of Dairy Science, v.83, p.278-284, 2000.

WHITE, E.C.; HINCKLEY, L.S. Prevalence of mastitis pathogens in goat milk. Small Ruminant Research, v.33, n.2, p.117-121, 1999.

Recebido em 16/12/11

Aceito em 15/1/13 